\title{
Patient and Caregiver Preferences for First-Line Treatments of Metastatic Non-Small Cell Lung Cancer: A Discrete Choice Experiment
}

\author{
Candice Yong (D) \\ $M$ Janelle Cambron- \\ Mellott $\mathbb{D}^{2}$ \\ Brian Seal $\mathbb{D}^{\prime}$ \\ Oliver Will $\mathbb{1}^{2}$ \\ Martine C Maculaitis (iD) ${ }^{2}$ \\ Kelly Clapp ${ }^{2}$ \\ Emily Mulvihill ${ }^{2}$ \\ Ion Cotarla $\mathbb{D}^{\prime}$ \\ Ranee Mehra (iD ${ }^{3}$ \\ 'AstraZeneca, Gaithersburg, MD, USA; \\ ${ }^{2}$ Cerner Enviza, Malvern, PA, USA; \\ ${ }^{3}$ University of Maryland Marlene and \\ Stewart Greenebaum Cancer Center, \\ Baltimore, MD, USA
}

Correspondence: M Janelle CambronMellott

Cerner Enviza, 5I Valley Stream Pkwy, Malvern, PA, 19355, USA

Tel +18162012190

Email Janelle.

CambronMellott@cernerenviza.com
Purpose: The approval of immune checkpoint inhibitors for metastatic non-small-cell lung carcinomas (mNSCLC) treatment has presented more care options. Therefore, it is important to identify the benefit-risk trade-offs patients and caregivers are willing to make among potential treatment options. This study quantified the preferences of patients and caregivers for attributes of mNSCLC treatment.

Methods: Patients with mNSCLC and caregivers completed an online survey assessing preferences using a discrete choice experiment. Respondents chose between hypothetical treatment profiles, with varying levels for 7 attributes associated with first-line treatment, including overall survival (OS), progression-free survival, select adverse events (AEs), and regimen (caregivers). Hierarchical Bayesian modeling was used to estimate attribute-level preference weights.

Results: Patients $(n=308)$ and caregivers $(n=166)$ most valued increasing OS from 11 to 30 months, followed by decreasing the risk of a serious AE (grade 3/4) that may lead to hospitalization from $70 \%$ to $18 \%$. These attributes were over twice as important to both sets of respondents as the other attributes measured. Patients and caregivers would accept increases in the risks of a serious $\mathrm{AE}$ (grade 3/4) from $18 \%$ to $70 \%$ and all grades nausea from $10 \%$ to $69 \%$ if OS increased by 16.8 and 4.0 months, respectively. The least valued attributes were all grades of pneumonitis (patients) and all grades of skin rash (caregivers). Conclusion: Patients and caregivers are willing to make trade-offs between efficacy and toxicity and may require up to 1.5 years of increased OS to accept a higher risk of AEs. These results can provide guidance to oncologists when engaging in shared-decision making discussions.

Keywords: immune checkpoint inhibitors, metastases, non-small-cell lung carcinomas, overall survival, patient preference, toxicities

\section{Introduction}

Lung cancer is associated with tremendous burden for patients and caregivers alike. Despite consistently declining rates over the past decade, it is estimated that this malignancy will account for more than 135,000 deaths and $22 \%$ of all cancer-related mortalities in the United States (US) in $2020,{ }^{1}$ which is nearly as many as the next most frequent causes of cancer-related deaths due to pancreatic, colorectal and breast, combined. ${ }^{1}$

The majority of lung cancer diagnoses in the US are non-small-cell lung carcinomas (NSCLC), ${ }^{2}$ and many patients with NSCLC are diagnosed with advanced disease. ${ }^{1}$ Patients diagnosed with metastatic NSCLC (mNSCLC) have a poor prognosis, with less than $6 \%$ of individuals surviving beyond 5 years. 
Traditionally, the first-line treatment for mNSCLC has been platinum-based doublet chemotherapy, with response rates of between $15-30 \%,{ }^{3,4}$ followed by taxane-based chemotherapy regimens as second-line therapy, with response rates of less than $10 \%{ }^{5,6}$ In the past decade, the treatment landscape for NSCLC has undergone substantial changes, with the introduction of immune checkpoint inhibitors that have demonstrated more durable responses among patients with mNSCLC.,

Because of these encouraging results, checkpoint inhibitors have become front-line therapy, with US Food and Drug Administration approval for pembrolizumab and atezolizumab as monotherapy in patients whose tumors have high programmed death-ligand 1 (PD-L1) expression (tumor proportion score [TPS] $\geq 50 \%$; pembrolizumab's approval was later expanded to include $\mathrm{TPS} \geq 1 \%$ ), as well as combination regimens with pembrolizumab or atezolizumab plus chemotherapy. Additionally, trials evaluating combinations of checkpoint inhibitors, with or without chemotherapy, have had promising results. ${ }^{9,10}$ This has led to approvals for nivolumab plus ipilimumab, with or without chemotherapy, as another first-line treatment option for patients with mNSCLC.

As new treatment options become available, decisionmaking among physicians, patients, and their caregivers becomes more complex and challenging. Governing medical bodies and patient advocacy agencies alike have promoted a shared decision-making model in oncology, with previous studies demonstrating the importance of assessing and incorporating patient preferences in treatment planning. ${ }^{11}$ Such preferences are critical in guiding discussions between providers and patients and their caregivers in the context of mNSCLC.

The burden of informal caregiving in cancer has been widely documented, including in the context of lung cancer. ${ }^{12-16}$ Caregivers play a critical role in caring for patients, as well as helping guide treatment and care decisions. Despite this, there have been few studies examining caregiver treatment preferences in the context of NSCLC. Critically, those studies that do exist have primarily focused on preferences in the era before the widespread introduction of checkpoint inhibitor agents and exclusively examined patient preferences. ${ }^{17-23}$

The need for contemporary data that includes the voices of patients and caregivers is particularly notable given the differences in side effect profiles between traditional chemotherapy regimens and newer immune checkpoint inhibitor therapies. ${ }^{24}$ This study sought to understand the trade-offs that patients and caregivers are willing to make regarding efficacy and toxicities associated with chemotherapy alone, immunotherapy (IO) alone, IO in combination with chemotherapy, and IO in combination with another IO for the first-line treatment of mNSCLC.

\section{Materials and Methods}

This was a multi-phase study, including: 1) literature review and concept elicitation interviews to identify key features (attributes) of treatment that affect treatment choice; 2) cognitive interviews to get feedback on the draft quantitative survey, and 3) execution of online, crosssectional quantitative stated preference surveys to measure preferences among patients and caregivers.

Patients and caregivers were recruited by convenience sampling via referrals from physician sites, cancer advocacy groups, social media outreach, and databases of patients who have opted in to be contacted for scientific studies. For the purposes of this research, participating patients and caregivers may have been, but were not required to have been, associated with one another. Patients and caregivers who participated in the concept elicitation interviews or the cognitive interviews were not included in the quantitative phase of the study.

Patients were included if they had a diagnosis of mNSCLC (stage IV), were aged 18-94 years, and selfreported receiving (past or current) or being scheduled to receive treatment with prescription medications for mNSCLC. A targeted recruitment of 300 patients was undertaken, evenly split between those under 65 years of age and those 65 years or older.

Caregivers were included if they were 18-94 years old, self-reported that they were currently caring for a patient with a diagnosis of mNSCLC (stage IV) between 18-94 years old, the patient they were caring for was receiving/ had received or was scheduled to receive treatment with prescription medications for $\mathrm{mNSCLC}$, they were the primary caregiver (mainly responsible or sharing responsibility equally for making treatment decisions and managing finances), did not receive payment as a form of employment for providing care to the patient (unless the patient was a family member), and provided care to the patient for $\geq 4$ hours per week. Quotas were set to recruit 75 caregivers for patients under 65 years old and 75 caregivers for patients 65 years or older.

Patients who reported having an epidermal growth factor receptor (EGFR) or anaplastic large-cell lymphoma kinase (ALK) mutation or having been treated with 
a tyrosine kinase inhibitor (TKI) were excluded, as were caregivers of patients with either of these mutations or who were treated with a TKI.

As the data from the interview and survey procedures were not linked with personally identifying information (exempt review category DHHS 45 CFR 46.104(d) category 2), this study was determined to be exempt from ethics review by Pearl IRB (Indianapolis, IN; IRB Study Number: 18-KANT-170) prior to starting data collection. This study was conducted in accordance with the Declaration of Helsinki, and informed consent was obtained from all respondents electronically.

\section{Survey Content}

Treatment preferences were evaluated using a discrete choice experiment (DCE) designed to estimate respondents' willingness to accept trade-offs among hypothetical treatment profiles. ${ }^{25}$ In a series of 12 choice tasks, respondents choose their preferred option among two side-by-side treatment profiles that vary with respect to their attribute levels. Each choice task included 7 attributes with 3-4 levels per attribute for each respondent group. As our qualitative research revealed that patients and caregivers had less awareness of PD-L1 status, attributes and levels were not split by PD-L1 level in the DCEs. The DCEs incorporated a balanced, overlap design. ${ }^{26}$

Attributes and levels were selected through an iterative, comprehensive process. First, a focused literature review of key clinical trials was undertaken ${ }^{27-41}$ to help guide the selection of attributes and levels. Concept elicitation interviews with 10 patients and 10 caregivers informed the final selection of attributes in the quantitative survey. Open-ended questions were used to identify factors that were important to patients and caregivers in treatment selection. Patients and caregivers were also probed on key attributes identified in the focused literature review. Survey questions were then designed based on these findings and finalized through cognitive interviews with 8 patients and 8 caregivers. Attributes were worded using non-technical language, including utilizing the Common Terminology Criteria for Adverse Events descriptions for adverse events (AEs). ${ }^{42}$ The levels selected for each attribute represented the range of performance seen in available therapies or expected for those under investigation, at the time of the study.

The operational definitions of the attributes and levels used in the DCE exercise for patients and caregivers are presented in Table 1. Whereas the DCE for both respondent groups included overall survival (OS), progression-free survival (PFS), risks of a serious AE (grade 3/4) that may lead to hospitalization, nausea, and pneumonitis, some of the attributes differed for the two respondent groups, due to differences identified in the qualitative research. Notably, whereas patients were concerned about the risks of neuropathy and fatigue, caregivers were more concerned about the risk of skin rash, possibly due to the efforts required on their part to treat the skin rash, and dosing schedule, as treatment was demanding and exhausting for the patient.

This study also collected data on patient and caregiver sociodemographic characteristics, patient health characteristics and treatment history, timing of cost discussions with physicians, and patient and caregiver out-of-pocket costs and financial assistance. A series of rating items were also included, in which respondents rated each attribute level included in the DCE on a 5 -point scale $(1=$ very bad, $5=$ very good). These items served two purposes: 1) they helped familiarize respondents to the attributes in the DCE choice exercise; and 2) they aided in identifying respondents who may have been inattentive in their responses.

\section{Statistical Analysis}

Descriptive statistics were calculated for all study variables, using means and standard deviations (SDs) for continuous variables and frequencies and percentages for categorical variables.

A hierarchical Bayesian (HB) model, utilizing a conditional logit underlying choice probability model and effects-coded attribute levels, was fitted to the choice data to derive mean preference weights. ${ }^{43}$ Willingness to make trade-offs was assessed by comparing the magnitude of change between levels of one attribute to the magnitude of change between levels in another attribute. The number of additional months of OS required to offset an increase in the risk of an $\mathrm{AE}$ from the lowest to the highest level was calculated for each AE. The conditional relative importance of each attribute was calculated for each respondent based on the difference between the respective minimum and maximum levels. As these relative importance estimates are ratio-scaled, the importance of one attribute can be directly compared to the importance of another attribute (eg, an attribute with a relative importance of $20 \%$ is twice as important as an attribute with a relative importance of $10 \%$ ). Further details on this methodology have been reported elsewhere. ${ }^{44}$ 
Table I Attributes and Levels Included in the Discrete Choice Experiment

\begin{tabular}{|c|c|c|c|}
\hline Attribute & Description Shown & $\begin{array}{l}\text { Levels Shown } \\
\text { to Patients }\end{array}$ & $\begin{array}{l}\text { Levels Shown to } \\
\text { Caregivers }\end{array}$ \\
\hline Median OS (months) & Survival (life expectancy) of $X$ months & \multicolumn{2}{|c|}{$\begin{array}{l}11 \\
17 \\
30\end{array}$} \\
\hline Median PFS (months) & Remain stable (cancer does not worsen) for $X$ months & \multicolumn{2}{|c|}{$\begin{array}{l}5 \\
8\end{array}$} \\
\hline Nausea (all grades) & $\begin{array}{l}\text { X\% risk of nausea affecting appetite, which could lead to dehydration and } \\
\text { malnutrition }\end{array}$ & \multicolumn{2}{|c|}{$\begin{array}{l}10 \% \text { risk } \\
36 \% \text { risk } \\
69 \% \text { risk }\end{array}$} \\
\hline $\begin{array}{l}\text { Neuropathy (all } \\
\text { grades) }\end{array}$ & $\begin{array}{l}\text { X\% risk of neuropathy involving numbness or/and pain, possibly severe, in } \\
\text { hands and feet which may limit daily activities }\end{array}$ & $\begin{array}{l}5 \% \text { risk } \\
16 \% \text { risk } \\
39 \% \text { risk }\end{array}$ & $\begin{array}{l}\text { (not included in } \\
\text { caregiver DCE) }\end{array}$ \\
\hline $\begin{array}{l}\text { Pneumonitis (all } \\
\text { grades) }\end{array}$ & $\begin{array}{l}X \% \text { risk of inflammation in the lungs, which could become serious and possibly } \\
\text { require temporary medical oxygen }\end{array}$ & \multicolumn{2}{|c|}{$\begin{array}{c}<1 \% \text { risk } \\
5 \% \text { risk } \\
8 \% \text { risk }\end{array}$} \\
\hline Fatigue (grade $3 / 4$ ) & $\begin{array}{l}X \% \text { risk of fatigue that is not relieved by rest and may limit your energy to care } \\
\text { for yourself (eg bathing, dressing, feeding self) }\end{array}$ & $\begin{array}{l}1 \% \text { risk } \\
6 \% \text { risk } \\
12 \% \text { risk }\end{array}$ & $\begin{array}{l}\text { (not included in } \\
\text { caregiver DCE) }\end{array}$ \\
\hline Skin rash (all grades) & $\begin{array}{l}\text { X\% risk of skin rash involving itching and/or burning, which could become } \\
\text { severe, limiting daily activities }\end{array}$ & $\begin{array}{l}\text { (not included in } \\
\text { patient DCE) }\end{array}$ & $\begin{array}{l}12 \% \text { risk } \\
17 \% \text { risk } \\
22 \% \text { risk }\end{array}$ \\
\hline Serious (grade 3/4) AE & $\mathrm{X} \%$ risk of a serious side effect that may lead to hospitalization & & $\begin{array}{l}\text { risk } \\
\text { risk } \\
\text { risk }\end{array}$ \\
\hline Regimen & & $\begin{array}{l}\text { (not included in } \\
\text { patient DCE) }\end{array}$ & $\begin{array}{l}4 \text { different } \\
\text { regimens }^{\mathrm{a}}\end{array}$ \\
\hline
\end{tabular}

Notes: Attributes included for only patients or only caregivers reflect differences in the attributes that were identified as most concerning in our prior qualitative research. ${ }^{a}$ Regimens included: (I) 2 to 8 hours of chair time receiving IV therapy every I to 3 weeks for 3 to 4 months then 45 to 75 minutes every 3 to 4 weeks; ( 2 ) I to 2 hours of chair time receiving IV therapy every 3 to 4 weeks for 3 to 4 months then 30 to 60 minutes every 2 to 4 weeks; (3) I to 4 hours of chair time receiving IV therapy every I to 3 weeks; (4) 30 to 60 minutes of chair time receiving IV therapy every 3 to 4 weeks.

Abbreviations: AE, adverse event; OS, overall survival; PFS, progression-free survival.

Bivariate analyses were performed to examine whether the relative importance of attributes differed by select subgroups of respondents using one-way analysis of variance tests. Subgroups examined included patient age $(<65$ vs $65+$ years), caregiver age ( $<44$ years vs $45-54$ years vs 55-64 years vs 65+ years), race/ethnicity (African American vs Asian vs Hispanic vs White, patients only), household income $(<\$ 50,000$ vs $\$ 50,000-\$ 99,999$ vs $\$ 100,000-\$ 149,999$ vs $\$ 150,000+)$, employment status (employed vs temporary leave of absence vs not employed vs retired, patients only), future treatment options for NSCLC (on last treatment option vs limited other treatment options vs several other treatment options), and patient insurance status (coverage through employer vs Medicare with Medigap vs Medicare without Medigap, caregivers only). Patients and caregivers were not directly compared, given the different sets of attributes and levels included in the DCE for each stakeholder group.

Data were analyzed using Sawtooth's Choice-Based Conjoint $\mathrm{HB}(\mathrm{CBC} / \mathrm{HB})$ Lighthouse Studio software version 9.8.0 for the DCE and using IBM SPSS version 23.0 for descriptive and bivariate statistics.

\section{Results}

Of the 349 patients and 217 caregivers who entered the survey, 308 patients and 188 caregivers qualified for and 
completed the survey. As 38 patients and 22 caregivers were flagged as potentially showing a lack of attention when completing the survey (ie, had 2 or more illogical responses to the attribute rating items, completed the survey in less than half of the median completion time, and/or completed the DCE section in less than 5 seconds per task), the preference weights were examined with and without these data. For patients, none of the preference weights differed significantly between the full sample and the sample without these 38 respondents. However, for caregivers, at least one of the preference weights differed between the full sample and the sample without the 22 caregivers. Therefore, 0 patients and 22 caregivers were excluded from the analysis, yielding final effective sample sizes of 308 patients and 166 caregivers.

The mean patient age was 63.6 years. The majority were married/in a committed relationship (69.5\%) and had completed at least some college $(85.7 \%) ; 35.1 \%$ were employed, of which $21.1 \%$ were on a temporary leave of absence. Almost three-quarters $(71.8 \%)$ were undergoing treatment with prescription medication at the time of study. Over one-third $(38.3 \%)$ of patients did not know their PD-L1 status, and $31.8 \%$ reported that their PD-L1 had not been discussed (Table 2).

The mean age for patients being cared for was 65.4 years, and the mean caregiver age was 57.6 years. The majority of caregivers had completed at least some college $(86.1 \%)$ and over half were employed (53.6\%), of which $4.2 \%$ were on a leave of absence (constituting nearly $10 \%$ of those employed). Most caregivers were patients' spouses or significant others $(65.1 \%)$. Nearly threequarters $(72.3 \%)$ of patients being cared for were undergoing treatment with prescription medication at the time of study. Almost half (49.4\%) of patients being cared for were unaware of their PD-L1 status, with another $24.7 \%$ reporting that their PD-L1 status had not been discussed by their physician (Table 2).

Patients reported an average annual out-of-pocket maximum of $\$ 2900.37 ; 30.8 \%$ had requested financial assistance for a cancer drug, and over one-third (35.7\%) indicated that they had been denied financial assistance. Four in ten patients $(40.6 \%)$ reported that they did not discuss treatment costs with the physician's office. Notably, $23.9 \%$ of patients rated the cost of cancer drugs as burdensome.

Caregivers reported that patients being cared for had an average annual out-of-pocket maximum of $\$ 3156.90$;
29.5\% had requested financial assistance for a cancer drug, and $28.9 \%$ had been denied financial assistance. Almost three-quarters (72.3\%) of caregivers helped support the patient financially; Financial burden included costs associated with: traveling for the patient's medical care $(30.1 \%)$, unpaid leave from work $(25.3 \%)$, cancer drugs $(18.6 \%)$, and other out-of-pocket expenses $(50.6 \%)$ (Table 3). Approximately one in four caregivers (29.5\%) reported that treatment costs were not discussed with the physician's office, and $15.7 \%$ reported being unsure about the timing of any treatment cost discussions.

\section{Preference Findings}

Patient and caregiver DCE results are shown in Figures 1 and 2, respectively. Improving median OS from 11 to 30 months was the most important attribute to patients and caregivers, followed by decreasing the risk of a serious $\mathrm{AE}$ (grade 3/4) that may lead to hospitalization from $70 \%$ to $18 \%$. Improvements in these attributes were over two times more important than improvements in each of the other attributes measured. Additionally, caregivers placed importance on a treatment regimen with shorter administration time and lower dosing frequency. Least important was decreasing the risk of all grades of pneumonitis from $8 \%$ to $<1 \%$ among patients and decreasing the risk of all grades of skin rash from $22 \%$ to $12 \%$ among caregivers (Figures 1A and 2A).

The differences among attribute-level preference weights demonstrate how much they are valued and show the trade-offs individuals are willing to make. For example, among patients, an increase in OS from 17 months to 30 months $(-0.65-[3.73]=-4.38)$ outweighed the reduction in risk of all grades nausea from $69 \%$ to $36 \%(0.22-[-0.79]=1.01)$ in importance for patients (Figure 1B). Among caregivers, an increase in OS from 11 months to 17 months $(-2.74-[-0.23]=-2.51)$ out weighed the reduction in risk from $8 \%$ to $5 \%$ in pneumonitis $(0.03-[-0.07]=0.10)$ in importance (Figure 2B). A 6-month gain in OS (from 11 to 17 months) outweighed a 5-month increase in PFS (from 5 to 10 months) for both patients $(-2.43$ vs -0.88$)$ and caregivers $(-2.51$ vs -1.01$)$.

Both patients and caregivers would require median OS improvements of 16.8 and 4.0 months to accept an increase in risks of a serious AE (grade 3/4) that may lead to hospitalization from $18 \%$ to $70 \%$ and all grades nausea from $10 \%$ to $69 \%$, respectively (Figures $1 \mathrm{C}$ and $2 \mathrm{C}$ ). 
Table 2 Sample Characteristics

\begin{tabular}{|c|c|c|}
\hline Variable & Patients & Caregivers \\
\hline & $(n=308)$ & $(n=166)$ \\
\hline Patient age, years, mean \pm SD & $63.6 \pm 11.7$ & $65.4 \pm 12.8$ \\
\hline Caregiver age, years, mean $\pm S D$ & - & $57.6 \pm 14.8$ \\
\hline Patient gender, male, $\mathrm{n}(\%)$ & $163(52.9)$ & $89(53.6)$ \\
\hline Caregiver gender, male, n (\%) & - & $55(33.1)$ \\
\hline $\begin{array}{l}\text { Marital status, n (\%) } \\
\text { Single/separated/divorced/widowed } \\
\text { Committed relationship/married }\end{array}$ & $\begin{array}{c}94(30.5) \\
214(69.5)\end{array}$ & $\begin{array}{l}35(21.1) \\
|3|(78.9)\end{array}$ \\
\hline $\begin{array}{l}\text { Education, } \mathrm{n}(\%) \\
\text { Less than college degree } \\
\text { College graduate or higher }\end{array}$ & $\begin{array}{l}117(38.0) \\
191(62.0)\end{array}$ & $\begin{array}{l}68(41.0) \\
98(59.0)\end{array}$ \\
\hline $\begin{array}{l}\text { Current employment status, } \mathrm{n}(\%) \\
\text { Employed (full or part time) } \\
\text { Employed, but currently on temporary leave of absence } \\
\text { Not employed } \\
\text { Retired } \\
\text { Other }\end{array}$ & $\begin{array}{l}43(14.0) \\
65(21.1) \\
42(13.6) \\
143(46.4) \\
15(4.9)\end{array}$ & $\begin{aligned} 82 & (49.4) \\
7 & (4.2) \\
18 & (10.8) \\
55 & (33.1) \\
4 & (2.4)\end{aligned}$ \\
\hline $\begin{array}{l}\text { Household income, } n(\%) \\
\text { Less than } \$ 50,000 \\
\$ 50,000-\$ 99,999 \\
\$ 100,000-\$ 149,999 \\
\$ 150,000+ \\
\text { Prefer not to answer }\end{array}$ & $\begin{array}{l}71(23.1) \\
103(33.4) \\
81(26.3) \\
39(12.7) \\
14(4.5)\end{array}$ & $\begin{array}{c}46(27.7) \\
62(37.3) \\
27(16.3) \\
31(18.7) \\
0(0)\end{array}$ \\
\hline $\begin{array}{l}\text { Patient's primary health insurance, } n \text { (\%) } \\
\text { Coverage through own, spouse's or parent's employer } \\
\text { Individual/family insurance plan } \\
\text { Medicaid/MediCal } \\
\text { Medicare/Medicare Advantage } \\
\text { Veteran's administration/TRICARE } \\
\text { Not sure/decline to answer }\end{array}$ & $\begin{array}{c}140(45.5) \\
35(11.4) \\
14(4.5) \\
114(37.0) \\
3(1.0) \\
2(0.6)\end{array}$ & $\begin{aligned} 64 & (38.6) \\
19 & (11.4) \\
5 & (3.0) \\
73 & (44.0) \\
3 & (1.8) \\
2 & (1.2)\end{aligned}$ \\
\hline $\begin{array}{l}\text { Race/Ethnicity, n (\%)* } \\
\text { African American/Black } \\
\text { Asian } \\
\text { American Indian } \\
\text { Hispanic } \\
\text { White } \\
\text { Other }\end{array}$ & $\begin{array}{c}39(12.7) \\
32(10.4) \\
4(1.3) \\
56(18.2) \\
183(59.4) \\
1(0.3)\end{array}$ & $\begin{array}{c}15(9.0) \\
15(9.0) \\
0(0.0) \\
23(13.9) \\
110(66.3) \\
3(1.8)\end{array}$ \\
\hline $\begin{array}{l}\text { Region, n (\%) } \\
\text { Northeast } \\
\text { Midwest } \\
\text { South } \\
\text { West }\end{array}$ & $\begin{array}{c}16(5.2) \\
28(9.1) \\
39(12.7) \\
225(73.1)\end{array}$ & $\begin{array}{c}7(4.2) \\
15(9.0) \\
32(19.3) \\
112(67.5)\end{array}$ \\
\hline $\begin{array}{l}\text { Urban area, } \mathrm{n}(\%) \\
\text { Major metropolitan/urban area }\end{array}$ & $126(40.9)$ & $66(39.8)$ \\
\hline
\end{tabular}

(Continued) 
Table 2 (Continued).

\begin{tabular}{|c|c|c|}
\hline \multirow[t]{2}{*}{ Variable } & Patients & Caregivers \\
\hline & $(n=308)$ & $(n=166)$ \\
\hline Suburb & $78(25.3)$ & $35(21.1)$ \\
\hline Rural/small city & $104(33.8)$ & $65(39.2)$ \\
\hline Duration of NSCLC disease, years, mean \pm SD & $1.8 \pm 1.6$ & $2.0 \pm 1.9$ \\
\hline \multicolumn{3}{|l|}{ Number of treatment regimen changes, $n(\%)$} \\
\hline Never undergone systemic treatment & $40(13.0)$ & $19(11.4)$ \\
\hline Currently on or completed first-line treatment & $47(15.3)$ & $35(21.1)$ \\
\hline Currently on or completed second-line treatment & $79(25.6)$ & $44(26.5)$ \\
\hline Currently on or completed third-line or later treatment & $142(46.1)$ & $68(41.0)$ \\
\hline \multicolumn{3}{|l|}{ PD-LI status ${ }^{\mathrm{a}}$} \\
\hline High PD-LI & $29(9.4)$ & $18(10.8)$ \\
\hline Low PD-LI & $53(17.2)$ & $20(12.0)$ \\
\hline Do not recall/not sure & $118(38.3)$ & $82(49.4)$ \\
\hline Not discussed & $98(31.8)$ & $4 \mid(24.7)$ \\
\hline \multicolumn{3}{|l|}{ Future treatment options for mNSCLC } \\
\hline On last treatment option & $65(21.2)$ & $36(21.7)$ \\
\hline Limited number of treatment options & $|4|(45.9)$ & $71(42.8)$ \\
\hline Several other treatment options & $85(27.7)$ & $56(33.7)$ \\
\hline
\end{tabular}

Notes: *Total may sum to $>100 \%$, as multiple options could be selected for race/ethnicity. ${ }^{\mathrm{a}} \mathrm{N}=10$ patients and $\mathrm{N}=5$ caregivers selected "None of the above" to the question about PD-LI status. ${ }^{b} \mathrm{~N}=16$ patients and $\mathrm{N}=3$ caregivers selected "None of the above" to the question about future treatment options.

Abbreviations: mNSCLC, metastatic non-small-cell lung carcinomas; SD, standard deviation.

Table 3 Financial Support and Burden Among Caregivers

\begin{tabular}{|l|c|}
\hline Variable & $\mathbf{N}=166$ \\
\hline Help support patient financially, yes, $n$ (\%) & $\mathrm{I} 20(72.3)$ \\
\hline $\begin{array}{l}\text { Burdensome out-of-pocket expenses outside the cost } \\
\text { of medication, yes, } \mathrm{n} \text { (\%) }\end{array}$ & \\
Cost of travel for treatment & $50(30.1)$ \\
Unpaid leave from work & $42(25.3)$ \\
Lodging/overnight stays & $15(9.0)$ \\
Other & $84(50.6)$ \\
None & $52(3 \mathrm{I} .3)$ \\
\hline Financial burden of out-of-pocket expenses, rating of 4 & \\
or 5, $\mathrm{n}$ (\%) & $3 \mathrm{I}(18.7)$ \\
Cost of cancer drugs & $14(28.0)$ \\
Cost of travel for treatment & $24(57.1)$ \\
Unpaid leave from work & $8(53.3)$ \\
Lodging/overnight stays & \\
\hline
\end{tabular}

Notes: Rating of financial burden of cost of cancer drugs, travel, lodging/overnight stays, and unpaid leave from work were rated on a scale from I=Not at all a burden to $5=\mathrm{A}$ great burden.

\section{Bivariate Analysis Results}

Statistically significant differences in the relative importance of reducing the risk of a serious $\mathrm{AE}$ (grade 3/4) that may lead to hospitalization from $70 \%$ to $18 \%$ were identified by patient employment status and future treatment options for NSCLC. Regarding employment status, reducing the risk of a serious $\mathrm{AE}$ (grade 3/4) that may lead to hospitalization from $70 \%$ to $18 \%$ was more important to employed patients than to patients on a temporary leave of absence or retired patients (38.1\% vs $30.1 \%$ and $29.9 \%$, respectively, $P=0.031$ ), but no different than unemployed patients (35.4\%). As such, employed patients require a greater increase in median OS to offset the increase in risk of a serious $\mathrm{AE}$ (grade 3/4) that may lead to hospitalization from $18 \%$ to $70 \%$ than patients on a temporary leave of absence, unemployed patients, or retired patients (25.1 vs 14.3 and 16.7 and 13.5 months, respectively; see Supplemental Figure 1).

With respect to future treatment options, reducing the risk of a serious AE (grade 3/4) that may lead to hospitalization from $70 \%$ to $18 \%$ was more important to patients who felt there were limited or several other treatment options available, compared with patients on their last treatment option $(32.4 \%$ and $35.3 \%$ vs $26.3 \%$, respectively, $P=0.010$ ), and was more important to caregivers of patients with limited other treatment options, compared with caregivers of patients on their last treatment option or 
A

Median OS - from 11 months to 30 months

Serious AE (grade $3 / 4$ ) that may lead to hospitalization - from $70 \%$ to $18 \%$

Nausea (all grades) - from $69 \%$ to $10 \%$

Median PFS - from 5 months to 10 months

Neuropathy (all grades) - from $39 \%$ to $5 \%$

Fatigue (grade $3 / 4$ ) - from $12 \%$ to $1 \%$

Pneumonitis (all grades) - from $8 \%$ to $<1 \%$

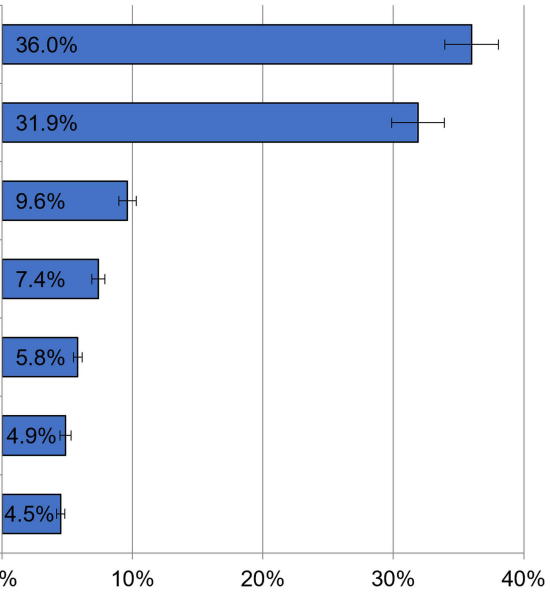

B

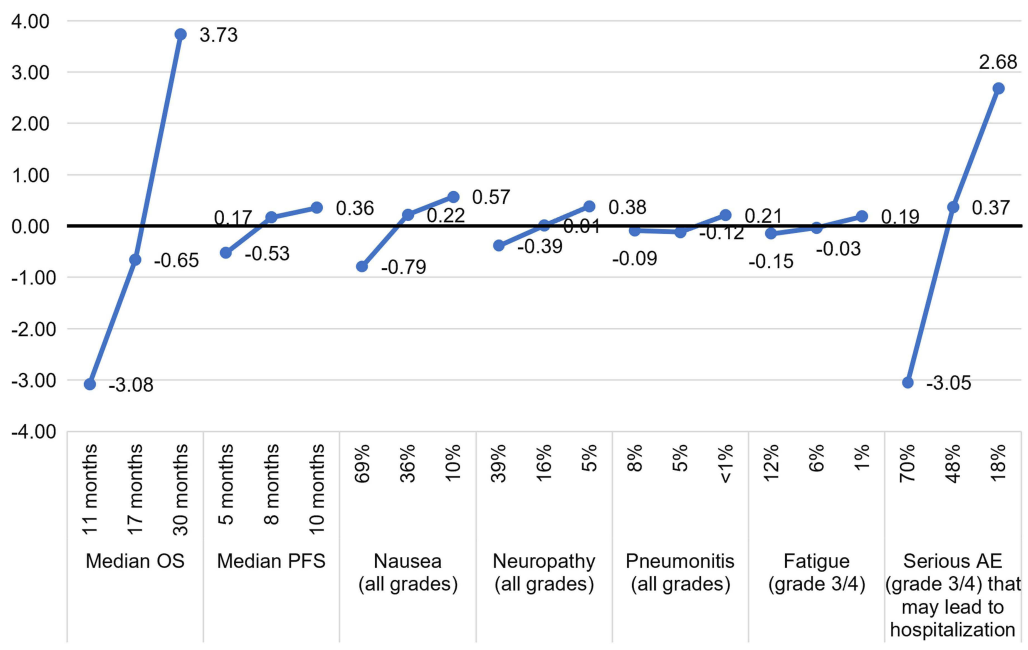

C

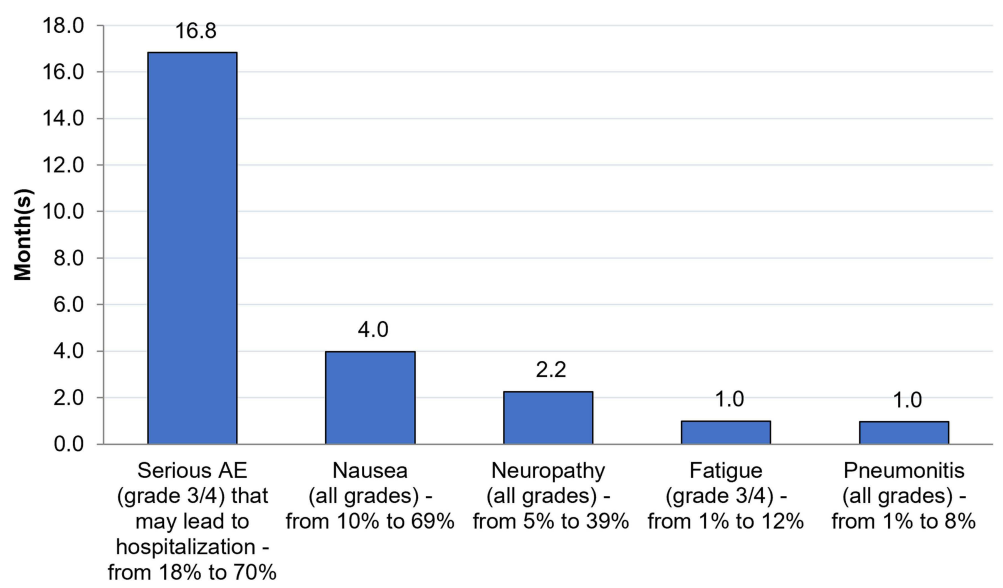

Figure I Patient preferences: $(\mathbf{A})$ relative importance of treatment attributes, $(\mathbf{B})$ attribute-level preference weights, and $(\mathbf{C})$ increases in number of OS months needed to accept increases in toxicity levels.

Notes: (A) $95 \%$ confidence intervals are shown. (B) Preference weights should not be interpreted by themselves. Instead, the magnitude of change within one attribute should be compared to change within another attribute.

Abbreviations: $A E$, adverse event, OS, overall survival, PFS, progression-free survival. 
A

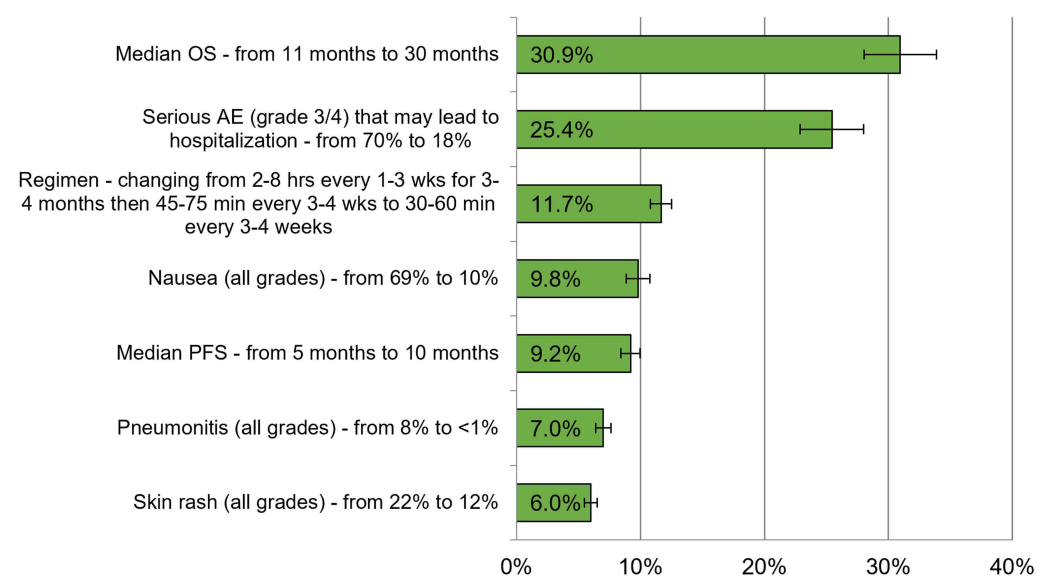

B

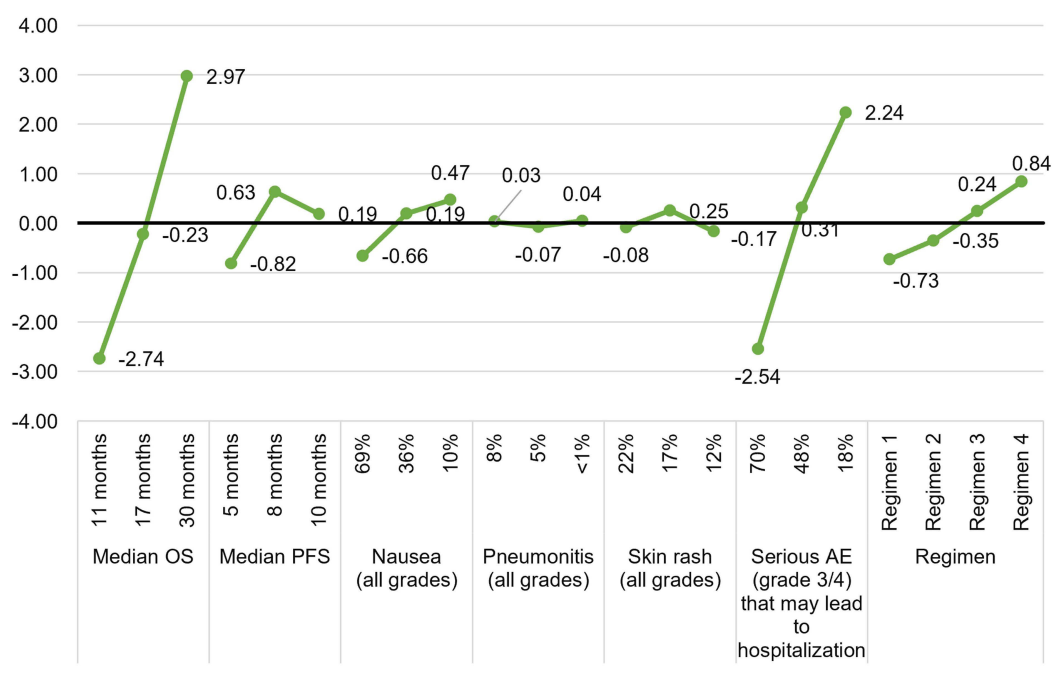

\section{C}

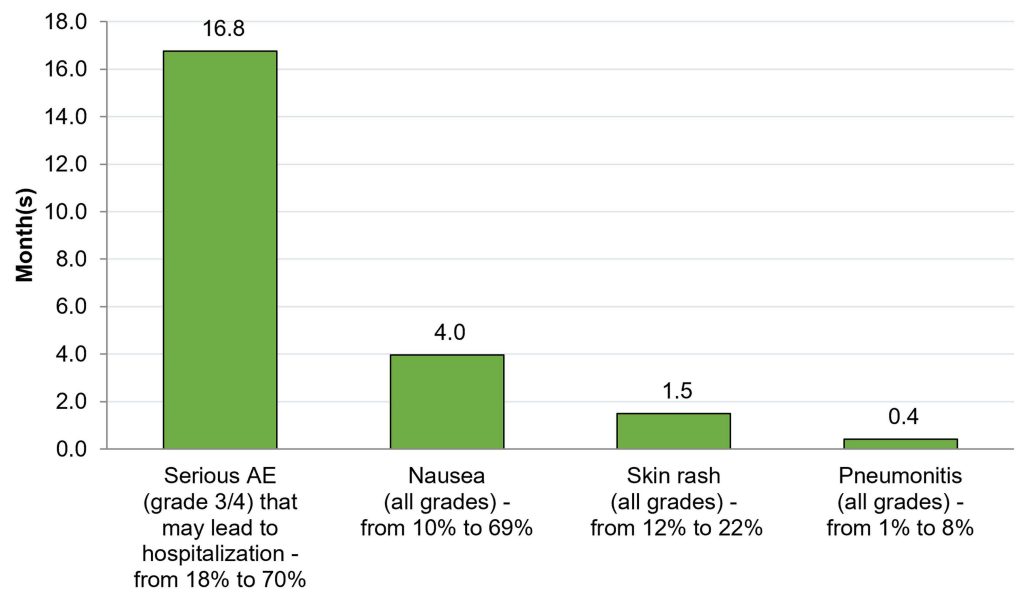

Figure 2 Caregiver preferences: (A) relative importance of treatment attributes, (B) attribute-level preference weights, and (C) increases in number of OS months needed to accept increases in toxicity levels.

Notes: (A) $95 \%$ confidence intervals are shown. (B) Regimens: (I) 2 to 8 hours of chair time receiving IV therapy every I to 3 weeks for 3 to 4 months then 45 to 75 minutes every 3 to 4 weeks; (2) I to 2 hours of chair time receiving IV therapy every 3 to 4 weeks for 3 to 4 months then 30 to 60 minutes every 2 to 4 weeks; (3) I to 4 hours of chair time receiving IV therapy every I to 3 weeks; (4) 30 to 60 minutes of chair time receiving IV therapy every 3 to 4 weeks. Preference weights should not be interpreted by themselves. Instead, the magnitude of change within one attribute should be compared to change within another attribute.

Abbreviations: AE, adverse event; OS, overall survival; PFS, progression-free survival. 
with several other treatment options $(29.8 \%$ vs $19.9 \%$ and $23.1 \%$, respectively, $P=0.006$ ).

In addition, with the exception of all grades nausea, patients who perceived having several other treatment options required the greatest increases in OS to accept the increased risk of toxicities compared to those who perceived they had limited other treatment options or that they were on their last treatment option. Caregivers who perceived that the patient they cared for had limited other treatment options required the greatest increases in OS to accept the increased risk of toxicities. Nevertheless, patients and caregivers required the largest increase in number of OS months to accept a risk of a serious $\mathrm{AE}$ (grade 3/4) that may lead to hospitalization (from 18\% to $70 \%$ ) than any other toxicity, regardless of the quantity of remaining treatment options perceived (Supplemental Figure 2).

Patient age, caregiver age, patient race/ethnicity, household income, and patient insurance status generally did not affect treatment preferences.

\section{Discussion}

This study helps to fill the gap in the literature on the treatment preferences of patients and caregivers in firstline mNSCLC given the newly available treatments in this space. Overall, this study found that patients and caregivers were both willing to accept increases in toxicity risks, within the ranges evaluated, in exchange for improvements in efficacy. Notably, improved OS was the most important attribute for both groups. Patients and caregivers both reported a willingness to make trade-offs between efficacy and toxicities when selecting a treatment. Specifically, this study demonstrated that to accept a higher risk of toxicities, patients and caregivers may require an increase in OS of up to a year and a half.

The current study found that among patients, increasing OS from 11 to 30 months was most important, followed by decreasing the risk of a serious AE (grade 3/4) that may lead to hospitalization from $70 \%$ to $18 \%$. These attributes were over three times more important than increasing PFS from 5 to 9 months and reducing the risks of grade $3 / 4$ fatigue from $12 \%$ to $1 \%$, and all grades nausea from $69 \%$ to $10 \%$, neuropathy from $39 \%$ to $5 \%$, and pneumonitis from $8 \%$ to $1 \%$. The same two attributes, OS and the risk of a serious AE that may lead to hospitalization, were also the most important among caregivers and more than twice as important as increasing PFS from 5 to 9 months, reducing the risks of all grades nausea from
$69 \%$ to $10 \%$, pneumonitis from $8 \%$ to $1 \%$, and skin rash from $22 \%$ to $12 \%$, and reducing the administration time and dosing frequency of treatment among this respondent group.

The consistent preference for survival benefit among both study groups reflects previous work in this domain, with Girones et al reporting that nearly half of their elderly respondents with lung cancer were willing to risk severe side effects, hospitalization, or death for a treatment that possessed the greatest chance of survival. ${ }^{20}$ Sun et al similarly reported the high importance of treatment efficacy among a cohort of patients with lung cancer; however, they noted the role of side effects, mode of administration, and treatment cost in guiding preferences, ${ }^{22}$ with further studies highlighting the complexity of preferences in relation to disease symptomatology. ${ }^{23}$ In addition, one of the few studies that have examined stakeholder preferences in the post-chemotherapy era reported that, although PFS was the most important treatment factor among patients with EGFR positive tumors, they would accept reduced PFS with TKIs in order to gain more favorable side effects and more convenient dosing. ${ }^{45}$

Notably, employed patients were less likely to choose a treatment with a high risk of a serious $\mathrm{AE}$ (grade 3/4) that may lead to hospitalization, compared with patients who were on a temporary leave of absence or retired. Indeed, employed patients required approximately 10 more months in OS to accept an increase in the risk of a serious AE (grade 3/4) that may lead to hospitalization from $18 \%$ to $70 \%$ than patients who were on a temporary leave of absence, unemployed, or retired. While it is important to note that many employed patients (approximately two-thirds) were not working at the time of the survey, possibly due to treatment, these results suggest that employment status can be an important driver of treatment preference.

This finding is in contrast with a previous study among those receiving treatment for recurrent ovarian cancer, which did not find employment status to be a driver of patient preferences. ${ }^{46}$ However, Jagsi et al found that among women diagnosed with breast cancer, those who were employed and undergoing aggressive treatment reported significant interference in their professional role. ${ }^{47}$ Thus, employed patients may possess significant concern of missing time from work should they be hospitalized, especially given that, for many individuals in the US, health insurance is provided through their employer. 
Among both respondent groups, preferences also differed based on perceived future treatment options for mNSCLC. Those individuals who perceived that there were additional treatment options were less likely to choose a treatment with a high risk of a serious $\mathrm{AE}$ (grade 3/4) that may lead to hospitalization, compared with those who perceived there to be no further treatment options. This suggests that, if there are several available treatment options, then patients and caregivers will minimize their risk of serious side effects. Notably however, as these options become more limited, both patients and caregivers are more willing to assume such risks. These findings provide insight into the many factors that can influence treatment preferences and the importance of shared decision-making with each patient.

The current study also found that treatment for mNSCLC poses a significant economic burden for caregivers in terms of both direct and indirect (eg, unpaid leave) costs. Further, maintaining insurance coverage appeared to be important to caregivers, as suggested by the nearly $10 \%$ of employed caregivers who were taking a leave of absence.

Finally, in the current study, over $40 \%$ of patients reported not discussing treatment costs with their oncologist, and $45 \%$ of caregivers either reported that treatment costs discussions did not occur or could not recall the timing of these conversation, which could imply that treatment costs were not discussed with caregivers. This finding contrasts with a previous study of oncologists where only $24 \%$ of oncologists noted that treatment costs were not discussed (manuscript in preparation). This disconnect is critical, given the escalating costs of oncology care and therapeutics, and emphasizes the need for more formal and systematic ways by which costs are addressed during medical visits.

The current study has limitations that should be acknowledged. Due to targeting a 50/50 split of patients under 65 years old and 65 years or older in both respondent groups, our sample over-represented patients under age 65. As the median age of patients in the current study was less than the median age of diagnosis in NSCLC of $71,{ }^{48}$ the results may not be generalizable to the entire mNSCLC population. Since the DCE methodology involves choosing between hypothetical treatment profiles based on a finite number of treatment attributes, an additional limitation is that actual treatment choices may differ from stated preferences. To mitigate this bias, qualitative research was conducted to include the attributes of most importance to patients and caregivers when making treatment decisions. Whereas attribute levels were developed based on available clinical evidence at the time of the study, it is possible that other attributes may exist or have become more prominent among the groups surveyed since this time. Finally, while the economic burden of treatment for mNSCLC is important for patients and caregivers, the current study was not designed to examine the impact of OOP costs on treatment preferences. Therefore, future research is needed to understand how economic burden plays a role in treatment preferences.

\section{Conclusion}

This study provides key insights into the trade-offs that patients and caregivers are willing to make between efficacy and toxicities in the context of currently available therapies for mNSCLC. The study demonstrated that, to accept a higher risk of toxicities, patients and caregivers required an increase in OS of up to 1.5 years, highlighting the importance of treatment efficacy in treatment decisionmaking among both groups.

The eliciting of patient and caregiver preferences remains an integral part of compassionate, comprehensive, patient-centered cancer care. Accordingly, the results of this novel study can help guide effective discussions between oncologists and patients/caregivers regarding treatments for mNSCLC.

\section{Abbreviations}

AE, adverse event; ALK, anaplastic large-cell lymphoma kinase; DCE, discrete choice experiment; EGFR, epidermal growth factor receptor; IO, immunotherapy; mNSCLC, metastatic non-small-cell lung carcinomas; NSCLC, non-small-cell lung carcinomas; OS, overall survival, PD-L1, programmed death-ligand 1; PFS, progression-free survival; TKI, tyrosine kinase inhibitor; TPS, tumor proportion score; US, United States.

\section{Data Sharing Statement}

The data that support the findings of this study are available for non-commercial use from the corresponding author, MJCM, upon reasonable request.

\section{Acknowledgments}

The authors acknowledge Kathleen Beusterien, MPH, of Cerner Enviza, for contributions to study design, analysis and reporting, and review of the manuscript outline, and Errol J. Philip, PhD for medical writing support. 


\section{Author Contributions}

All authors made a significant contribution to the work reported, whether that is in the conception, study design, execution, acquisition of data, analysis and interpretation, or in all these areas; took part in drafting, revising or critically reviewing the article; gave final approval of the version to be published; have agreed on the journal to which the article has been submitted; and agree to be accountable for all aspects of the work.

\section{Funding}

This study was sponsored by AstraZeneca. Medical writing support was provided by Errol J. Philip, PhD, in accordance with Good Publication Practice (GPP3) guidelines and funded by AstraZeneca.

\section{Disclosure}

Candice Yong and Brian Seal were employees and shareholders of AstraZeneca at the time of study conduct. Ion Cotarla is an employee and shareholder of AstraZeneca. M. Janelle Cambron-Mellott, Oliver Will, Martine C. Maculaitis, Kelly Clapp, and Emily Mulvihill are employees of Cerner Enviza, which received funding from AstraZeneca for conducting the study and analysis and for manuscript preparation. Ranee Mehra is an employee of University of Maryland Marlene and Stewart Greenebaum Cancer Center, which received research funding from AstraZeneca for consulting on the study. Ranee Mehra's institution has also received research funding outside of this work from AstraZeneca and Merck, and she has received consulting fees from Rakuten Medical, outside of this work. The authors report no other conflicts of interest in this work.

\section{References}

1. Surveillance Epidemiology and End Results (SEER) Program. Cancer Stat Facts: Common Cancer Sites. National Cancer Institute; 2020.

2. American Cancer Society. What is Lung Cancer?; 2019.

3. Kelly K, Crowley J, Bunn PA Jr, et al. Randomized Phase III trial of paclitaxel plus carboplatin versus vinorelbine plus cisplatin in the treatment of patients with advanced non-small-cell lung cancer: a Southwest Oncology Group trial. J Clin Oncol. 2001;19 (13):3210-3218. doi:10.1200/JCO.2001.19.13.3210

4. Schiller JH, Harrington D, Belani CP, et al. Comparison of four chemotherapy regimens for advanced non-small-cell lung cancer. $N$ Engl J Med. 2002;346(2):92-98. doi:10.1056/NEJMoa011954

5. Fossella FV, DeVore R, Kerr RN, et al. Randomized Phase III trial of docetaxel versus vinorelbine or ifosfamide in patients with advanced non-small-cell lung cancer previously treated with platinum-containing chemotherapy regimens. The TAX 320 Non-Small Cell Lung Cancer Study Group. J Clin Oncol. 2000;18(12):2354-2362.
6. Weiss JM, Stinchcombe TE. Second-line therapy for advanced NSCLC. Oncologist. 2013;18(8):947-953. doi:10.1634/theoncologist.2013-0096

7. Domagała-Kulawik J. Immune checkpoint inhibitors in non-small cell lung cancer - towards daily practice. Adv Respir Med. 2018;86 (3):144-150. doi:10.5603/ARM.2018.0022

8. Wang S, Hao J, Wang H, Fang Y, Tan L. Efficacy and safety of immune checkpoint inhibitors in non-small cell lung cancer. Oncoimmunology. 2018;7(8):e1457600. doi:10.1080/216240 2X.2018.1457600

9. Reck M, Ciuleanu T-E, Dols MC, et al. Nivolumab (NIVO) + ipilimumab (IPI) +2 cycles of platinum-doublet chemotherapy (chemo) vs 4 cycles chemo as first-line (1L) treatment (tx) for stage IV/recurrent non-small cell lung cancer (NSCLC): checkMate 9LA. $J$ Clin Oncol. 2020;38(15_suppl):9501. doi:10.1200/JCO.20 20.38.15_suppl.9501

10. Reck M, Schenker M, Lee KH, et al. Nivolumab plus ipilimumab versus chemotherapy as first-line treatment in advanced non-smallcell lung cancer with high tumour mutational burden: patient-reported outcomes results from the randomised, open-label, Phase III CheckMate 227 trial. Eur $J$ Cancer. 2019;116:137-147. doi:10.1016/j.ejca.2019.05.008

11. Havrilesky LJ, Alvarez Secord A, Ehrisman JA, et al. Patient preferences in advanced or recurrent ovarian cancer. Cancer. 2014;120 (23):3651-3659. doi:10.1002/cncr.28940

12. Borges EL, Franceschini J, Costa LH, Fernandes AL, Jamnik S, Santoro IL. Family caregiver burden: the burden of caring for lung cancer patients according to the cancer stage and patient quality of life. J Bras Pneumol. 2017;43(1):18-23. doi:10.1590/s1806-37562 016000000177

13. Bradley CJ. Economic burden associated with cancer caregiving. Semin Oncol Nurs. 2019;35(4):333-336. doi:10.1016/j. soncn.2019.06.003

14. Geng HM, Chuang DM, Yang F, et al. Prevalence and determinants of depression in caregivers of cancer patients: a systematic review and meta-analysis. Medicine (Baltimore). 2018;97(39):e11863. doi:10.1097/MD.0000000000011863

15. Kent EE, Rowland JH, Northouse L, et al. Caring for caregivers and patients: research and clinical priorities for informal cancer caregiving. Cancer. 2016;122(13):1987-1995. doi:10.1002/ cncr.29939

16. Wood R, Taylor-Stokes G, Smith F, Chaib C. The humanistic burden of advanced non-small cell lung cancer (NSCLC) in Europe: a real-world survey linking patient clinical factors to patient and caregiver burden. Qual Life Res. 2019;28(7):1849-1861. doi:10.1007/ s11136-019-02152-6

17. Blinman P, Hughes B, Crombie C, et al. Patients' and doctors' preferences for adjuvant chemotherapy in resected non-small-cell lung cancer: what makes it worthwhile? Eur J Cancer. 2015;51 (12):1529-1537. doi:10.1016/j.ejca.2015.05.022

18. Mühlbacher AC, Bethge S. Patients' preferences: a discrete-choice experiment for treatment of non-small-cell lung cancer. Eur J Health Econ. 2015;16(6):657-670. doi:10.1007/s10198-014-0622-4

19. Silvestri G, Pritchard R, Welch HG. Preferences for chemotherapy in patients with advanced non-small cell lung cancer: descriptive study based on scripted interviews. BMJ. 1998;317(7161):771-775. doi:10.1136/bmj.317.7161.771

20. Gironés R, Torregrosa D, Gómez-Codina J, Maestu I, Tenias JM, Rosell R. Lung cancer chemotherapy decisions in older patients: the role of patient preference and interactions with physicians. Clin Transl Oncol. 2012;14(3):183-189. doi:10.1007/s12094-012-0782-6

21. Islam KM, Anggondowati T, Deviany PE, et al. Patient preferences of chemotherapy treatment options and tolerance of chemotherapy side effects in advanced stage lung cancer. BMC Cancer. 2019;19 (1):835. doi:10.1186/s12885-019-6054-x 
22. Sun $\mathrm{H}$, Wang $\mathrm{H}, \mathrm{Xu} \mathrm{N}$, et al. Patient preferences for chemotherapy in the treatment of non-small cell lung cancer: a multicenter discrete choice experiment (DCE) study in China. Patient Prefer Adherence. 2019;13:1701-1709. doi:10.2147/PPA.S224529

23. Bridges JF, Mohamed AF, Finnern HW, Woehl A, Hauber AB. Patients' preferences for treatment outcomes for advanced nonsmall cell lung cancer: a conjoint analysis. Lung Cancer. 2012;77 (1):224-231. doi:10.1016/j.lungcan.2012.01.016

24. Dubey S, Brown RL, Esmond SL, Bowers BJ, Healy JM, Schiller JH. Patient preferences in choosing chemotherapy regimens for advanced non-small cell lung cancer. J Support Oncol. 2005;3(2):149-154.

25. Bridges JF, Hauber AB, Marshall D, et al. Conjoint analysis applications in health-a checklist: a report of the ISPOR Good Research Practices for Conjoint Analysis Task Force. Value Health. 2011;14 (4):403-413. doi:10.1016/j.jval.2010.11.013

26. Johnson FR, Lancsar E, Marshall D. Constructing experimental designs for discrete-choice experiments: report of the ISPOR Conjoint Analysis Experimental Design Good Research Practices Task Force. Value Health. 2013;16:3-13.

27. Goldberg SB, Balmanoukian A, Chaft J. 3086 A Phase 1b study to evaluate the safety and antitumor activity of MEDI4736 in combination with tremelimumab in patients with advanced NSCLC. Eur $J$ Cancer. 2015;51:S627. doi:10.1016/S0959-8049(16)31727-0

28. Brahmer JR, Rodriguez-Abreu D, Robinson AG. Progression after the next line of therapy (PFS2) and updated OS among patients (pts) with advanced NSCLC and PD-L1 tumor proportion score (TPS) $\geq 50 \%$ enrolled in KEYNOTE-024. J Clin Oncol. 2017;35:9000.

29. Hellmann MD, Ciuleanu TE, Pluzanski A. Nivolumab (nivo) + ipilimumab (ipi) vs platinum-doublet chemotherapy (PT-DC) as first-line (1L) treatment (tx) for advanced non-small cell lung cancer (NSCLC): initial results from CheckMate 227. Cancer Res Treat. 2018;78:CT077.

30. Merck Pharmaceuticals. KEYTRUDA ${ }^{\circledR}$ (Pembrolizumab) Prescribing Information; 2019.

31. Danson S, Middleton MR, O'Byrne KJ, et al. Phase III trial of gemcitabine and carboplatin versus mitomycin, ifosfamide, and cisplatin or mitomycin, vinblastine, and cisplatin in patients with advanced nonsmall cell lung carcinoma. Cancer. 2003;98 (3):542-553. doi: $10.1002 / \mathrm{cncr} 11535$

32. Gandhi L, Rodríguez-Abreu D, Gadgeel S, et al. Pembrolizumab plus chemotherapy in metastatic non-small-cell lung cancer. $N$ Engl J Med. 2018;378(22):2078-2092. doi:10.1056/NEJMoa1801005

33. Garon EB, Rizvi NA, Hui R, et al. Pembrolizumab for the treatment of non-small-cell lung cancer. $N$ Engl $J$ Med. 2015;372 (21):2018-2028. doi:10.1056/NEJMoa1501824

34. Hellmann MD, Ciuleanu TE, Pluzanski A, et al. Nivolumab plus ipilimumab in lung cancer with a high tumor mutational burden. $N$ Engl J Med. 2018;378(22):2093-2104. doi:10.1056/NEJMoa1801946

35. Jotte R, Cappuzzo F, Vynnychenko I, et al. Atezolizumab in combination with carboplatin and Nab-paclitaxel in advanced squamous NSCLC (IMpower131): results from a Randomized Phase III Trial. $J$ Thorac Oncol. 2020;15(8):1351-1360. doi:10.1016/j.jtho.202 0.03 .028

Patient Preference and Adherence

\section{Publish your work in this journal}

Patient Preference and Adherence is an international, peer-reviewed, open access journal that focusing on the growing importance of patient preference and adherence throughout the therapeutic continuum. Patient satisfaction, acceptability, quality of life, compliance, persistence and their role in developing new therapeutic modalities and compounds to optimize clinical outcomes for existing disease

Submit your manuscript here: https://www.dovepress.com/patient-preference-and-adherence-journa
36. Reck M, Rodríguez-Abreu D, Robinson AG, et al. Pembrolizumab versus chemotherapy for PD-L1-positive non-small-cell lung cancer. $N$ Engl J Med. 2016;375(19):1823-1833. doi:10.1056/ NEJMoa1606774

37. Rittmeyer A, Barlesi F, Waterkamp D, et al. Atezolizumab versus docetaxel in patients with previously treated non-small-cell lung cancer (OAK): a Phase 3, open-label, multicentre randomised controlled trial. Lancet. 2017;389(10066):255-265. doi:10.1016/S01406736(16)32517-X

38. Socinski MA, Bondarenko I, Karaseva NA, et al. Weekly nab-paclitaxel in combination with carboplatin versus solvent-based paclitaxel plus carboplatin as first-line therapy in patients with advanced non-small-cell lung cancer: final results of a Phase III trial. J Clin Oncol. 2012;30(17):2055-2062. doi:10.1200/ JCO.2011.39.5848

39. Socinski MA, Jotte RM, Cappuzzo F, et al. Atezolizumab for first-line treatment of metastatic nonsquamous NSCLC. $N$ Engl $J$ Med. 2018;378(24):2288-2301. doi:10.1056/NEJMoa1716948

40. Mok TSK, Wu YL, Kudaba I, et al. Pembrolizumab versus chemotherapy for previously untreated, PD-L1-expressing, locally advanced or metastatic non-small-cell lung cancer (KEYNOTE-042): a randomised, open-label, controlled, Phase 3 trial. Lancet. 2019;393(10183):1819-1830. doi:10.1016/S01406736(18)32409-7

41. Paz-Ares L, Luft A, Vicente D, et al. Pembrolizumab plus chemotherapy for squamous non-small-cell lung cancer. $N$ Engl $J$ Med. 2018;379(21):2040-2051. doi:10.1056/NEJMoa1810865

42. U.S. Department of Health and Human Services. Common Terminology Criteria for Adverse Events (CTCAE) Version 5.0; 2017.

43. Hauber AB, Gonzalez JM, Groothuis-Oudshoorn CG, et al. Statistical methods for the analysis of discrete choice experiments: a report of the ISPOR Conjoint Analysis Good Research Practices Task Force. Value Health. 2016;19(4):300-315. doi:10.1016/j.jval.2016.04.004

44. Joko T, Nagai Y, Mori R, et al. Patient preferences for anti-vascular endothelial growth factor treatment for wet age-related macular degeneration in Japan: a discrete choice experiment. Patient Prefer Adherence. 2020;14:553-567. doi:10.2147/PPA.S228890

45. Bridges JF, la Cruz M, Pavilack M, et al. Patient preferences for attributes of tyrosine kinase inhibitor treatments for EGFR mutation-positive non-small-cell lung cancer. Future Oncol. 2019;15(34):3895-3907. doi:10.2217/fon-2019-0396

46. Donovan KA, Greene PG, Shuster JL, Partridge EE, Tucker DC. Treatment preferences in recurrent ovarian cancer. Gynecol Oncol. 2002;86(2):200-211. doi:10.1006/gyno.2002.6748

47. Jagsi R, Abrahamse PH, Lee KL, et al. Treatment decisions and employment of breast cancer patients: results of a population-based survey. Cancer. 2017;123(24):4791-4799. doi:10.1002/cncr.30959

48. Howlader N, Noone AM, Krapcho M, et al. SEER Cancer Statistics Review, 1975-2017. Bethesda, MD: National Cancer Institute; 2020.

states are major areas of interest for the journal. This journal has been accepted for indexing on PubMed Central. The manuscript management system is completely online and includes a very quick and fair peer-review system, which is all easy to use. Visit http:// www.dovepress.com/testimonials.php to read real quotes from published authors. 